\title{
My Health Record: a community pharmacy perspective
}

\section{Shane Jackson \\ National vice president, Pharmaceutical Society of Australia, Canberra \\ Clinical senior lecturer, Division of Pharmacy, School of Medicine, University of Tasmania, Hobart}

\section{Gregory Peterson}

Professor of Pharmacy, School of Medicine,

University of Tasmania, Hobart

Adjunct professor of Pharmacy, University of Canberra

\section{Keywords}

electronic health records, pharmacists

Aust Prescr 2019;42:46-7 https://doi.org/10.18773/ austprescr.2019.009
Digital healthcare records aim to facilitate the delivery of safe, efficient and effective health care while connecting different points of the healthcare system so that information can be shared securely. These records can impact on almost every aspect of healthcare delivery. This includes how healthcare professionals and patients interact with each other, how health information is stored and used, and how patients manage their own health through electronic apps and devices. Due to the rapid evolution of digital health care, today's health professionals, including pharmacists, need an understanding of the expectations, opportunities and challenges that digital health technologies present.

The My Health Record system is one of the first initiatives in the world aimed at delivering an electronic, personally controlled health record for the entire population of a country. The Australian Government determined that by the end of 2018 every Australian would have a My Health Record unless they chose not to.

One of the key potential benefits of a national electronic health record will be a reduction in the risk of medication misadventure (adverse drug events and medication errors), which results in more than 230,000 Australians being admitted to hospital each year. These hospitalisations cost the healthcare system at least $\$ 1.2$ billion annually. However, this represents the tip of the iceberg because this figure does not include general practice or specialist visits, the cost of investigations, or presentations to community pharmacy.

Pharmacists already store information such as drugdispensing histories that may not be available to other healthcare professionals, including the patient's GP. By making this information securely available through My Health Record to other healthcare providers, pharmacists can contribute to a comprehensive overview of the patient's medicine use, including medication adherence and persistence inferred by the frequency of dispensing. This may improve healthcare outcomes. In particular, access to dispensing records and other drug-related histories can facilitate effective and efficient medicines reconciliation at transitions of care, such as admission to and discharge from hospital. An Australian study found that two-thirds of initial hospital medication charts contain at least one error, and access to community pharmacy dispensing records reduces the time taken to identify and correct these errors. ${ }^{2}$

Most pharmacists and authorised pharmacy staff will interact with the My Health Record system at the point of dispensing through the use of compliant dispensing software. The provision of comprehensive dispensing information to My Health Record will give a more complete picture of the patient's medicines, as well as an insight into the way they are taken, particularly if the pharmacist supplements the record of prescribed drugs by recording over-the-counter and complementary medicines. This information may be valuable to the patient's GP, specialists, hospital clinicians, the patient and their carer. ${ }^{3}$

Historically, community pharmacists have not had ready access to verifiable clinical information about the patient's medical conditions, pathology or imaging results, or the indication for the prescribed medicine, to help inform their clinical decision making. This clinical information will give the pharmacist a greater opportunity to improve the use of medicines in the Australian community and usefully contribute to reducing medication misadventure, particularly at transitions of care. However, there will be challenges imposed by factors such as compatibility with pharmacy workflow and the need for adequate clinical knowledge and skills to leverage information in electronic health records to improve the quality use of medicines and patient outcomes. ${ }^{4,5}$

The system architecture of My Health Record allows pharmacists to contribute dispensing records and event summaries. With advances in the usability of pharmacy computer systems and professional service recording platforms, event summaries could in the future describe a consultation with a pharmacist about a minor ailment, a MedsCheck Service or a Home Medicines Review. This will ensure that services delivered by a pharmacist in a community pharmacy can be added (with patient consent) to My Health Record, and then be viewed by other health professionals so reducing the risk of fragmentation of care. Advances in secure message delivery can also ensure that details of these consultations can be provided to other healthcare providers when the patient deems it appropriate. Health information exchange systems, such as My Health Record, can facilitate the integration of 
pharmacists into care teams to improve the use of medicines and patient outcomes. ${ }^{6}$ Systems enabling communication and the sharing of health information should facilitate good working relationships between health professionals, and enable collaborative patientcentred care. ${ }^{7}$ In Kansas, community pharmacists were able to use a state health information exchange to collect hospital discharge information from patients' electronic medical records to facilitate medication reviews and the identification of drug therapy problems following discharge. As a result, there was a statistically significant reduction in hospital readmissions. ${ }^{8}$ However, there is currently a paucity of published information describing the outcomes of the integration of shared electronic health records in community pharmacies. Further research is needed. 9,10

Having pharmacy information available to prescribers and clinical information available to pharmacists will provide all professions with an opportunity to enhance the continuum of the quality use of medicines in Australia. A comprehensive postimplementation evaluation should be performed to assess whether this potential is fulfilled. $<$

Shane Jackson is a clinical reference lead with the Australian Digital Health Agency.

\section{REFERENCES}

1. Roughead L, Semple S, Rosenfeld E. Literature review: medication safety in Australia. Australian Commission on Safety and Quality in Health Care: Sydney; 2013. https://www.safetyandquality.gov.au/publications/ literature-review-medication-safety-in-australia [cited 2019 Mar 1]

2. Tompson AJ, Peterson GM, Jackson SL, Hughes JD, Raymond K. Utilizing community pharmacy dispensing records to disclose errors in hospital admission drug charts. Int J Clin Pharmacol Ther 2012;50:639-46. https://doi.org/ 10.5414/CP201720

3. Wright DJ, Twigg MJ. Community pharmacy: an untapped patient data resource. Integr Pharm Res Pract 2016;5:19-25. https://dx.doi.org/10.2147/FIPRP.S83261

4. Nelson SD, Poikonen J, Reese T, El Halta D, Weir C. The pharmacist and the EHR. J Am Med Inform Assoc 2017;24:193-7. https://doi.org/10.1093/jamia/ocw044

5. Hughes CA, Guirguis LM, Wong T, Ng K, Ing L, Fisher K. Influence of pharmacy practice on community pharmacists integration of medication and lab value information from electronic health records. J Am Pharm Assoc 2011;51:591-8. https://doi.org/10.1331/JAPhA.2011.10085
6. Pellegrin K, Chan F, Pagoria N, Jolson-Oakes S, Uyeno R, Levin A. A statewide medication management system: health information exchange to support drug therapy optimization by pharmacists across the continuum of care. Appl Clin Inform 2018;9:1-10. https://doi.org/10.1055/s-0037-1620262

7. Keller ME, Kelling SE, Cornelius DC, Oni HA, Bright DR. Enhancing practice efficiency and patient care by sharing electronic health records. Perspect Health Inf Manag 2015;12:1b.

8. Fanizza FA, Ruisinger JF, Prohaska ES, Melton BL. Integrating a health information exchange into a community pharmacy transitions of care service. J Am Pharm Assoc 2018;58:442-9. https://doi.org/10.1016/j.japh.2018.02.012

9. Bacci JL, Berenbrok LA. Innovative advances in connectivity and community pharmacist patient care services: implications for patient safety. Pharmacotherapy 2018;38:867-74. https://doi.org/10.1002/phar.2148

10. Hohmeier KC, Spivey CA, Boldin S, Moore TB, Chisholm-Burns M. Implementation of a health information exchange into community pharmacy workflow. J Am Pharm Assoc 2017;57:608-15. https://doi.org/ 10.1016/j.japh.2017.05.009

\section{FURTHER READING}

Pearce R, Whyte I. Electronic medication management: is it a silver bullet? Aust Prescr 2018;41:32-3. https://doi.org/10.18773/ austprescr.2018.012
Wheeler AJ, Scahill S, Hopcroft D, Stapleton H. Reducing medication errors at transitions of care is everyone's business. Aust Prescr 2018;41:73-7. https://doi.org/10.18773/ austprescr.2018.021 